\title{
Estado, Representação, Guerra. Algumas considerações sobre a concepção Hobbesiano-Schmittiana do Político
}

\author{
State, representatio, war. Some considerations \\ regarding to the Hobbesian-Schmmitian conception \\ concerning the politician
}

\author{
Jorge E. Dotti ${ }^{1 *}$
}

\begin{abstract}
Resumo
O presente texto objetiva estabelecer uma comparação entre a reflexão de Hobbes e Carl Schmitt e para tanto se utilizará dos conceitos de Estado, Representação e guerra, noções centrais para a compreensão de questões políticas e jurídicas da modernidade e da contemporaneidade. Espera-se, ao final, apresentar uma concepção nova desses termos de modo a iluminar reciprocamente a reflexão atual, seja de Hobbes assim como a de Carl Schmitt.
\end{abstract}

Palavras-chave: Estado, Representação, guerra, Hobbes, Carl Schmitt

\begin{abstract}
This paper aims to establish a comparison between the reflection concept of Hobbes and Carl Schmitt under Politic's place and which as use the concepts kind "State", "Representation" and "War", notions central to understanding political and legal issues of modernity and contemporaneity for understand each other. It is expected to end, present a new design of these terms in order to illuminate one another reflection current under Hobbes as well as under Carl Schmitt.
\end{abstract}

Key-words: State, Representation, War, Hobbes, Carl Schmitt

1. O pensamento de Hobbes e o de Schmitt em torno ao que este conceitualizou como o Político se aglutinam na resposta que o Estado pode dar ao problema da guerra simultaneamente civil e internacional que caracteriza a gênesis do mundo moderno, não obstante hajam variado as configurações do bélico,

1 *Professor Titular de Filosofia Política da Universidade de Buenos Aires/Argentina, pesquisador do CONICET, email: jorge.e.dotti@hotmail.com. Tradução de Danilo Vaz-Curado R.M. Costa (UNICAP/PE).

Ano $13 \cdot$ n. $1 \cdot$ jan./jun. $2013-9$ 
o acompanham até o presente, traçando uma continuidade entre a metafísica subjetivista da modernidade e a pós-metafísica (ou metafísica do pós) contemporânea.

No conceito e na realidade da guerra ambos visualizam o ponto de convergência tanto do conflito entre o elemento que põe em perigo a convivência pacífica ordenada legalmente, por um lado, e o sistema institucional que deve lhe garantir, isto é: a soberania estatal, por outro. Aí reside sua importância. Desenvolveremos na continuidade algumas considerações sobre a resposta que Hobbes e Schmitt dão ao problema da correlação entre a ordem estatal e a guerra, a qual enquadra a questão da Representação. De alguma maneira, intentaremos também contribuir para a avaliação do sentido que a tríade conceitual do título destas páginas pode manter nas condições presentes.

Em que pese suas vivências e reflexões pertençam a momentos históricos diversos, ambos os pensadores estão motivados por um mesmo problema: o de como neutralizar um enfrentamento radical e violento em grau máximo, cujos participantes impugnam sem meios termos aos princípios existenciais básicos (isto é, as visões religiosas, político-jurídicas, morais, culturais em geral sobre as quais repousa a convivência) do outro, que se tornouinimigo não político, mas inimigo total, porque a interpretação e aplicação desses mesmos princípios, que este faz, resultam incompatíveis com as daquele. Trata-se de uma confrontação entre posições irmanadas, porém, antitéticas e inconciliáveis, porque ambos os adversários codividem o mesmo princípio ou conceito fundamental e divergem sem conciliação possível na interpretação e consequente efetivação particular das conotações mais gerais. É o núcleo básico da guerra civil, porém o universalismo moderno das posições antagônicas envolve uma dimensão mais ampla: também é uma guerra internacional. A mesma familiaridade que aproxima os adversários frente a outras legitimações e regimes consequentes entre si (v.g. nos séculos XVI e XVII: o cristianismo frente ao islamismo) implica a necessidade de destruir a ameaça de uma alternativa tanto mais ameaçadora, quanto próxima (protestantismo, calvinismo e igrejas reformistas em ge- 
ral, catolicismo); porém, a dimensão universalista das posições em disputa traz consigo alinhamentos internacionais (nações ou unidades políticas menores de religião católica contra seus equivalentes, defensoras da Reforma). A afirmação de uma posição é conceitualmente possível apenas se destrói a outra (um pouco mais além as circunstâncias históricas obrigaram ao estabelecimento de acordos, tréguas, situações de pacificação do conflito).

$\mathrm{Na}$ época da guerra total já plenamente desenvolvida (desde a metade do século XIX até a data do presente texto, ainda quando as últimas décadas conhecem uma variante peculiar: a violência pós-moderna), a neutralização do inimigo equivale habitualmente a uma destruição física do mesmo (destruição material, de suas cidades, riquezas, etc. e biológica, de seus contingentes humanos), ao menos no nível de aniquilamento e intimidação, como para esterilizar toda atitude de resistência e, sobretudo, para evitar que, nos acordos pacificadores, o derrotado possa exercer algum tipo de resistência às condições do vencedor. Dado que ambos invocam a justiça, a razão, a ciência, o progresso, a criação de uma nova humanidade, a regeneração/purificação, o céu na terra e coisas similares, nenhum tipo de justiça cabe ao derrotado e a conduta justa para com ele é aniquilá-lo. A sequência das guerras mundiais do século vinte é ilustrativa: não menos é a violência endêmica e superficialmente moderada da Guerra Fria e da bipolaridade em geral (que longe estava de excluir guerras quentes com participação ativa de terceiros ao conflito e ou forças expedicionárias, de ocupação ou semelhantes); e a recente guerra total em sua fase atual, a da violência pós-moderna, adota estratégias e táticas heterogêneas e maleáveis segundo condições, recorrendo a uma multiplicidade de meios e de ações: é uma violência intermitente, de tipo tanto tradicional (intervenção de exércitos nacionais com ocupação de território), como de tipo de guerrilha, como de tipo terrorista (sem uniformes militares) e antiterrorista (que operam como forças estatais uniformizadas ou como paramilitares); com meios violentos e com meios assepticamente tecnológicos (Cyber war), em todo o espaço, sem teleologia precisa (que regime se propõe a instalar?), com tempos 
imprevisíveis; diríamos: combatividade polifônica, fragmentária, brutal, anômica, sempre em fluxo, politopológica, espetacular. Violência pós-moderna, contudo, que não desmente, ao contrário, confirma o caráter irrestrito, incontido, disperso, indiscriminado, indiscriminadamente abarcante, que a ars belli contemporânea herda de seus antecessores modernos que, por sua vez, impelem ao cumprimento com espírito epocal.

2. Hobbes e Schmitt, em suas respectivas situações, assumem como premissa básica de seu pensamento o conflito existencial extremo; o que põe os princípios constitutivos de uma convivência, que cada comunidade assume como próprios e retores de sua legalidade, ante o perigo de uma mudança radical que os desvirtua ou diretamente os elimina e substitui por outros. A tarefa que define a soberania é neutralizar esta ameaça e a salvaguardar a ordem ameaçada. Por certo, definir assim as coisas é uma consideração de tipo geral que, de algum modo, serve para toda a ordem política: porém Hobbes e Schmitt pensam o político e teorizam a questão atendendo à especificidade da mesma, em função das condições epocais. Em seu caso, então, o fenômeno ou configuração do político que motiva seus pensamentos (e condutas) é o Estado. Ao primeiro, nos inícios do ciclo estatal; ao segundo, no fenecimento do mesmo.

Pensadores da ordem política moderna, desse modo, compreendem que, no ator da modernidade, repousa o conflito total, e não possuem ilusões sobre a possibilidade de que uma marcha natural das coisas, o dinamismo ontológico universal por si mesmo, seja capaz de eliminar a conflitividade das relações humanas. Particularmente quando, como na época moderna, o ator privilegiado é o sujeito-substância que eleva o ato de autofundamentar-se ao fundamento do conhecimento e da prática. Sobre suas pretensões orgulhosas de fazer da exteriorização-realização de si mesmo, a pedra angular do mundo se apoia na ordem a construir segundo os ensinamentos da razão, e por fim, também da justiça.

Ainda quando durante certo período (digamos: entre a guerra civil inglesa e a Revolução Francesa: ainda que também 
com posteridade a esta em alguns casos) a guerra moderna se desenvolve em conformidade a tais regras de direito internacional e os conflitos têm uma marca duelista, de violência limitada e, a seu modo respeitando o adversário (ou seja, responde a doutrina da guerre em forme), sem dúvida, as características distintivas da belicosidade moderna são as de ser topologicamente ilimitável, pois está presente em todos os distintos âmbitos e permeia não apenas as dimensões institucionais intrinsecamente políticas e jurídicas, mas também - e com efeitos arrasadores - os espaços sociais e ainda (ou sobretudo) as pessoas privadas: criminalizadora do inimigo; de uma intensidade sem limite ou contenção, já que suas variações respondem exclusivamente ao cálculo da conveniência de intensificar-se ou melhor, enervar-se, de violar as regras jusnaturalistas ou melhor, respeitá-las segundo se julgue qual é o melhor caminhão para alcançar a meta buscada, a aniquilação do adversário. Em suam, os contendentes da guerra total estão impelidos pelo dinamismo da ratio que sustenta a consciência livre: expansão reflexionante (o outro como espelho do próprio si-mesmo) que guarda pela harmonia com o gesto de autodeterminação (Selbstbehauptung), com o qual o sujeito se constitui como fundamento de si mesmo e liquida a transcendência (cogito ergo sum, ou melhor: sou o que sou); inevitabilidade da negação absoluta de toda a alteridade que não confirma a própria identidade reflexionante, isto é, do que simultaneamente é e não é a própria imagem e se configura como ameaça existencial. Ante ela, a resposta racional - e o correspondente latino que propomos é - pugno, ergo sum.

Cada um em seu momento histórico, Hobbes e Schmitt são conscientes disso. A compreensão epocal que os une é a de que a configuração subjetiva moderna tem na conflitividade a condição intrínseca de seu próprio sentido. Sabem que a subjetividade é um ponto de partida insuprimível se é que se quer pensar o político; sabem também que se não se neutraliza essa mesma conflitividade inerente ao sujeito, nenhuma ordem política pode sustentar-se em termos de garantias de uma convivência pacífica e segura. Desse modo, ainda quando o conflito, em suas varia- 
das gradações, está presente em toda a forma de sociabilidade, não obstante, a guerra moderna se caracteriza pela mesma aspiração de totalidade que mobiliza o sujeito que se pensa a si mesmo como substância-fundamento, para o qual tudo é uma autoposição reduplicante de si como do outro de si. O esforço teórico por neutralizar este dinamismo, que não pode ser assumido como base indelével de qualquer pensamento sobre o político, é enorme em ambos. A história mostra que a visão teológico-política que compartilham para legitimar o Estado como dique de contenção, parece condenada ao fracasso.

3. Dada a importância que essas questões têm na conformação teórica e histórica dos problemas que tratam nos permitimos insistir nelas. Os conflitos distintivamente moderno são simultaneamente bella intestina e guerras internacionais, entre rivais motorizados por visões de mundo universais e absolutas, por ideologias e legitimações de ordem (neste caso, tanto secular como espiritual), porém entendidas de um modo tal que as interpretações e consequentes aplicações ou concretizações na realidade resultam antitéticas e incompatíveis. As hermenêuticas são plurais: cada consciência tem direito à sua, uma vez que se derrubou o sistema de mediação entre o universal e o particular tradicionalmente constituído pelo Papa e a Igreja como instituição mediadora entre o Céu e a Terra, entre transcendência e imanência. Esta mediação já não é aceita por aqueles que invocam o mesmo princípio cristão (Hobbes - isto é por demais conhecido - o resumo coerentemente: Jesus ist the Christ). A amplitude semântica das conotações religiosas, morais, sociais, estéticas, socioeconômicas, culturais em geral se organiza a partir de interpretações divergentes, então, porém ambas também totalizadoras, abarcando todas as dimensões da convivência. A guerra civil tende, desse modo, nesta diversidade de significados antitéticos que os contendentes atribuem, desde as respectivas posições enfrentadas, a um mesmo princípio ou conceito universal, o fio condutor dos elementos que conformam a constelação ideológica do conflito; por isso mesmo, é também guerra internacional, já que os corpos de ideologia moderno são supranacionais, totalizantes e se projetam 
ilimitadamente porque são respaldados pela verdade da ciência que é da justiça, são totalizantes (inicialmente os países católicos contra os protestantes; crentes de um mesmo credo porém de nações diversas contra outros na mesma condição; logo, iluministas contra reacionários, por motivos de limites políticos: mais tarde, o liberalismo em expansão global, o socialismo em suas diversas variantes, os fascismos, com as adesões que respondem a conotações ideológicas e não as pertenças estatais, respeitadas, estas, apenas quando coincidem com aquelas).

A guerra ideológica e multidimensional com a qual se abre o mundo moderno, de caráter total incipiente, porém nítido em sua potencialidade, prolepse da violência futura, aparece como concomitante a outros fenômenos distintivos dos começos da modernidade, porém nenhum como ela traz à luz a nota distintiva da nova visão da política e da sociabilidade. Por fim, o novo ator da prática humana: a vontade (isto é, a subjetividade como faculdade de decisão e ação livre), que o Eu assume como a marca específica de sua condição de fundamento absoluto e autossuficiente. Precisamente essa liberdade subjetiva está na origem mesmo do impulso construtivo da ordem estatal e, como indissoluvelmente unido ao Estado, como o outro rosto Jânico da vontade, também é fonte e instância legitimante do impulso a rechaçar a obediência a todo mandato a que a consciência privada (santuário da liberdade individual) não lhe dê seu consentimento. Disso se segue que o conflito seja essencialmente constitutivo da forma de convivência política que as diversas consciências livres considerem adequada a razão; e que essa mesma razão (ou seja, a interpretação que a consciência dá de quais são as ações racionais e quais não) desconheça todo limite distinto do que ela mesma decida que cabe aceitar ou não. Desse modo, qualquer tipo de violência termina sendo justa, contanto que no foro interno se the qualifique de racional; e é próprio dessa metafísica sustentar as decisões e ações da consciência-vontade numa universalidade vazia, em abstrações que rapidamente cada sujeito pode tornar pleno e assim concretizar com suas perspectivas e interesses particulares, contanto que as apresente, mesmo que vagamente, 
conforme as conotações abstratas desse universalismo formalista (v.g. liberté, égalité, fraternité tem sua realização enquanto a guilhotina e a ditadura terrorista como no sistema de educação pública laica e gratuita: atribuir tudo a uma marcha progressista da história gera mais problema do que esta crença crê solucionar).

A nota característica da violência irrestrita que se segue da potestade omninoda do Eu é que, lançado a defender a razão e a justiça contra os que julga - ou seja, opinam - que os agridem, inflexivelmente deslegitima o agressor, em quem não pode visualizar nada distinto que um expoente da máxima irracionalidade, da injustiça e de criminalidade inexpiáveis. Quando seu outro não é a exteriorização de si mesmo, numa repetição tautológica, é um agressor. Não pode tolerar frente a si um adversário exclusivamente político, cujas condutas estão respaldadas no mesmo direito e na mesma legitimidade; ou seja, um inimigo contra o qual se combate, porém ao que se lhe reconhece sua dignidade. O Eu em ação se justifica porque, em seu inimigo, não encontra mais que a degradação do ser humano, a fera selvagem, inimigo do gênero humano, ao que apenas cabe aniquilar, destruir ou extirpar da sociedade definitivamente, sem cerimônias (para recordar as fórmulas de Locke).

O processo da conflitividade extrema, simultaneamente civil e internacional, obscurece as regras da guerra que simultaneamente os teóricos do direito internacional moderno estão estipulando, sempre conscientes da generosidade com que chamam direito a normas que poderiam fundar-se no Deus/Razão, porém que carecem de um executor e garante aceito por todos os Estados (únicos titulares do ius ad bellum) neste mundo. A rigor, a harmonização de ambas as dimensões se produz exclusivamente em virtude de uma divisão especial planetária, que permite ordenar as relações interestatais. É o que Schmitt chama - é bem sabido - o nomos da terra peculiar da modernidade.

O processo não conhece arrestos e desemboca coerentemente na violência pós-moderna (planetária, fluida, endêmica, desubstancializada, ilimitada, desrespeitosa frente a qualquer distinção e ou pauta de contenção, por muito que se proclame o 
contrário). A guerra total, simultaneamente civil-internacional, é a forma moderna e a pós-moderna do conflito extremo e ilimitado em suas diversas modalidades, desde as guerras civis e religiosa da primeira modernidade até chegar ao atual terrorismo dos terroristas sem uniformes militares e o terror dos antiterroristas que operam como exércitos nacionais e/ou paramilitares.

4. Hobbes e Schmitt, um no ponto inicial e o outro no terminal deste desenvolvimento, são os teóricos da neutralização deste conflito, ambos são plenamente conscientes de que todo o intento de fazê-lo - e cujo primeiro passo é compreender e teorizar o sentido e as condições para isso - tem que partir do reconhecimento de que esta marca epocal condiciona toda política, pois o contexto exigido pelo conceito do político.

Diziamos que a guerra total como traço histórico-conceitual básico do mundo, instaurada como racionalidade bélica no século vinte, remete a estas manifestações juvenis de conflitividade irrestrita especificamente moderna, fortemente ideologizada, como as guerras religiosas européias dos séculos XVI e XVII, às vicissitudes da Revolução Inglesa no século XVII; e, por certo, às guerras da Revolução Francesa, ou melhor, desencadeadas por ela; esses anos (1792-1815) de guerras civis européias, donde a profissão de fé e a fidelidade a uma igreja ou a uma nação ou a mabas vão cedendo o privilégio de legitimar o conflito ao andaime categorial iluminista.

Vejamos agora, que tanto Hobbes quanto Schmitt percebem que é nos atores sociais que cobiçam sob o pano de fundo de um universalismo formal suas pretensões particularistas, erigidas desde a noção chave de uma liberdade subjetiva (a da consciência na invisibilidade do foro interno e na visibilidade de suas projeções não-políticas: economia, opinião pública, educação, etc) e na interiorização privatista da mediação entre o universal e o particular, por sob a forma da convicção pessoal; por fim, ambos coincidem em que é nas corporações, facções e associações de diverso tipo, porém prioritariamente não estatais de onde se gera e produz o dinamismo da conflitividade irrestrita. Na Inglaterra de 1600, Hobbes experimentou a antecipação deste fenômeno que 
lhe sucederia logo após; a vivência Schmitt durante três quartos do século vinte, ao contrário, é já a da violência ilimitada e abarcadora de todas as dimensões da existência. Semelhante belicosidade crescentemente totalizante e poliforma (todo o espaço ou âmbito é campo de batalha; todas as condutas e ações são válidas) é o dinamismo que vai operando a transição definitiva desde uma lógica da guerra aceitavelmente regulada em conformidade às pautas de contenção próprias do direito internacional moderno, a justificação de procedimentos e condutas bélicas liberadas de toda restrição em termos jurídicos e éticos. Ao largo deste processo se vão eliminando todas as distinções de tipo político, jurídico, culturais em geral e bélicas em particular, características do que Schmitt chamou o Ius publicum Europaeum: combatentes e população civil; teatros de operações e zonas pacificadas; contendentes e civis; exércitos, agrupações guerrilheiras, células terroristas; em última instância: paz e guerra.

Em suma: não obstante as distâncias históricas e as peculiaridades biográficas que os separam, o problema de como neutralizar essa violência em seu princípio constitutivo é a motivação que Hobbes e Schmitt compartilham dentro de uma confiança comum na qual o Estado (por instaura, no primeiro, e por conservar vigente com as adaptações exigidas por um mundo pós-estatal, no segundo) a resposta adequada.

5. Se tomarmos em mente que a soberania estatal é uma relação hierárquica dos homens entre si e deste com o espaço, a resposta pacificadora que oferece o Estado moderno é geopolítica.

O soberano deve diferenciar e manter delimitados dois espaços contíguos e diversos: o estatal, como espaço interior pacificado, e o exterior ou internacional, de onde não apenas a guerra tem seu sentido e justificação, senão que, nas zonas não civilizadas, que persistem no estado natural, é racional comportar-se em guerra sem respeito a nenhuma regra que a da sobrevivência e a vitória. Ao mesmo tempo em que a visão moderna do direito oferece a solução, ela simultaneamente a faz impossível. Distinção e indistinção são constitutivas da ontologia e da antropologia mo- 
dernas: apenas pode autolimitar-se quem tem a potestade de não fazê-lo. Aqui radica a chave da Soberania. É plena no interior do Estado e constitui-se a identidade jurídica do Estado mesmo frente a seus iguais, as outras ordens estatais, porém, por isto mesmo não existe um soberano único internacional. Seria contraditório com a lógica da estatalidade. O sujeito moderno é plenipotenciário para estabelecer o espaço pacificado da ordem civil, alcançando o máximo de proteção pessoal possível no Estado, porém também goza (conceitualmente) do mesmo poder pleno para entrar em guerra com seus iguais. O Estado é um macro-indivíduo e procede da mesma maneira: autoprotegendo-se mediante a paz e a guerra.

Dito de outro modo: apenas pode limitar-se quem pode superar o limite que se impõe a si mesmo; porém, o poder para fazer-lo envolve também o de extralimitar-se. Este sujeito tem uma capacidade ilimitável para totalizar o conflito. Disto se segue também a simbiose entre revolução (na origem do Estado) e ordem estatal como sistema institucional antirrevolucionário, uma dialética evidente em Hobbes e Schmitt, dois defensores da soberania como força neutralizadora da ação revolucionária (essa capacidade expansiva incontrolável, própria do sujeito-vontade livre que, havendo-se elevado a fundamento absoluto, subroga na imanência a omnipotência de Deus transcendente). Deste modo, a intrínseca capacidade expansiva infinita da substância derruba o traçado destas linhas divisórias geopolíticas, peculiares da estatalidade clássica.

Esta reordenação do espaço, que em Hobbes é plausível e alcança um grau aceitável de realização histórica, na época de Schmitt é impraticável e alcança seu maior sentido como um esforço por compreender o sentido da estatalidade, com o propósito de resgatar o resgatável dela, isto é, destacar o motivo central que poderia e deveria manter (alguma) eficácia numa época pós-estatal.

A ordem geopolítica que propõe, pressupõe definições e distinções nítidas, e delimitações precisas em sua teorização, com aceitável vigência na realidade das coisas humanas (o caráter pro- 
visório e efêmero da vigência e o acatamento das decisões é uma das dificuldades que dão sentido à lei como cifra da convivência). Sua distinção chave, então, é expressa em consideração ao Estado pela dupla de conceitos dentro-fora; ou seja, a demarcação entre o interior estatal pacificado pela soberania e o espaço exterior onde impera a lei natural, não a civil, pois não há soberano ou juiz comum na terra, senão exclusivamente no Céu, porém não é razoável nem cristão esperar a intervenção direta de Deus nas questões de seres livres.

Hobbes e Schmitt coincidem que a resposta ao conflito inerente à situação excepcional radica na instauração de um ordenamento espacial baseado em definições com força de lei, na formulação e no respeito de diferenças claras, no traçado nítido de delimitações precisas (por provisória que seja a vigência e a efetividade desses elementos; uma dificuldade que confere sentido ao político jurídico é a questão da decisão soberana e da lei como cifra da convivência humana).

A geopolítica hobbesiana, ao colocar a guerra no estado de natureza a-dikelógico (onde impera o direito de todos contra todos, ale não há justiça; porém, tampouco injustiça, já que não há propriedade privada) anula o recurso à justiça que todo o contendente faz definindo-se a si mesmo como justo e ao seu inimigo como injusto, porém priva de sentido o fato de que esta distinção entre agressor injusto e agredido justo, entre Estado em guerra, pode ser estabelecida por uma presumida autoridade universal, seja espiritual (como o Papa), seja política (alguma nação que se proclame vicária da justiça). $\mathrm{O}$ Direito natural que todos têm de autopreservar-se compreende o direito de todo agente a fazer a guerra se é que se vê existencialmente obrigado a isso, para alcançar sua própria preservação, entendida está em termos não biológicos, senão de um viver espiritual e concretamente não de acordo com valores intercambiáveis e funcionais ao relativismo, senão a princípios intransigentes em virtude da função existencial que cumprem, tal como frequentemente estão expressos na carta constitucional do Estado a que se pertence, porém não apenas nela. 
Hobbes descarta a tradicional distinção entre as guerras justas e injustas e, por fim, ataca as argumentações que estão na base da guerra total: os justos têm direito de aniquilar os injustos.

O mesmo faz Schmitt. A desideologização do conflito civil-internacional está na base mesma da identidade específica do inimigo implementada na dualidade conceitual que define o político. Se trata de um inimigo político, e não religioso, moral, econômico, e menos ainda pessoal; e é tal que é aquele contra o qual se decide uma situação existencial extrema. Ao tratar-se de inimizade política, os adversários estão em pé de igualdade política e jurídica, sem que nenhum deles, nem um terceiro por cima das partes, possa alegar e determinar quem é o vigário da justiça; ambas as posições, então, conduzem a uma determinação da atividade bélica submetida a limitações e regulações para as quais a dimensão especial é constitutiva.

Em ambos os pensadores, o espaço é a verdade da ordem política estatal; a decisão soberana define e restringe ou regula a liberdade de deslocamento pelo espaço e o tempo (neste caso, uma liberdade exclusivamente metafísica), uma atitude de fluidez que aos humanos lhes cabe por natureza, em conformidade à estrutura ontológica do universo, a infinitude do cosmos e ao movimento livre dos átomos, tal como o demonstra a nova ciência. Ao circunscrever a especialidade própria como território nacional, e traçar a divisória entre um dentro (a paz) e um fora (a guerra), o soberano também tem que submeter o tempo da ordem civil às exigências do político, enquanto nas condições de normalidade, como - e sobretudo - nas de crise. Num regime de mandato-obediência como o do Estado, o soberano regula a temporalidade teológico-política (que é verdadeiramente significativa para o político), e suas decisões devem afastar a aceleração utópica, desativar a invocação do futuro e impor prudentemente um ritmo político que neutraliza a urgência. Decidir politicamente (instaurar/restaurar a estatalidade) é limitar o fluxo, desacelerar a mobilidade irrestrita que distingue os dois dinamismos incompatíveis com o político schmittiano: o da metafísica numerária (a decisão política em sumo grau tem que sobrepor-se à lógica da merca- 
doria e da insubstancialidade dos significantes) e o da revolução (a aceleração extrema em chave messiânica). A decisão soberana refreia, desacelera, e, assim, sustenta o Estado. Porém também é impulso à ação rápida que neutraliza o estado de exceção; e se bem que nas Cartas constitucionais esteja contemplado um tipo de resposta anormal para as situações de extrema anormalidade (as normas para a necessidade (as normas para necessidade e urgência), a impressão sobre as medidas a tomar é inevitável, e a decisão excepcional sobre o excepcional responde, no relativo aos seus aspectos concretos nas situações específicas, a capacidade prudencial de decisão soberano.

6. É necessária uma especificação ulterior a respeito da configuração dos espaços pacificados e das zonas de onde provêm os enfrentamentos violentos na modernidade clássica.

Os primeiros são postos pelas fronteiras e limites políticos do Estado nacional, enquanto que os segundos apresentam uma diversidade importante. Quando a guerra tem lugar no continente europeu e durante o período que estamos pensando (principalmente o século XVIII anterior aos acontecimentos franceses), autoridades e exércitos atuam em conformidade com uma determinação jusinternacionalista que restringe a violência ${ }^{2}$. Porém, quando os enfrentamentos acontecem no estado de natureza verdadeiramente, nas águas livres e nas terras livres (onde não há a ordem civil segundo o modelo europeu), a violência é tão livre e ilimitada como o espaço onde se desenvolve: beyond the border, tudo vale. Quando se instaura a prática da guerra total,

\footnotetext{
Se trata de la praxis de la típica guerra de movimientos rigurosamente determinados, con formaciones y tácticas dispuestas con precisión geométrica; guerra ajedrecística en el campo de batalla y de mucha diplomacia y presiones políticas en los gabinetes; a su modo, también acotada también por motivos económicos, ya que son tropas pagas, formadas por connacionales y por mercenarios, y los altos gastos que conllevan condicionan las estrategias, de modo de sensatamente evitar que se entablen choques inútiles (por ejemplo, cuando las posiciones alcanzadas por las tropas en el campo de batalla no arrojan dudas sobre cuál será el resultado del combate); combates inclusive violentos, por cierto, pero siempre fieles a un espíritu coreográfico y a las limitaciones en la capacidad destructiva de los armas utilizadas.
} 
também o espaço europeu será considerado espaço natural, livre e permissivo.

Isso acontece na época de Schmitt. A diferença da situação hobbesiana, em seu caso, a guerra na Europa entre países politicamente homogêneos e sustentados em princípios de legitimidade similares, por fim, os conflitos aceitavelmente regulados, típicos da modernidade clássica anterior à Revolução Francesa, feneceram. O teólogo-político e jurista da estatalidade sabe que a guerra total é um factum ineliminável, e que o Estado poderá conservar algo de seu sentido prístino apenas se ressemantiza a ideia de soberania absoluta, objetivando com ela dar uma resposta política às condições críticas da primeira pós-guerra na Europa e neutralizar a ameaça da violência incontrolável. O fracasso a este respeito justifica a consciência schmittiana do fim do ciclo histórico do Estado (claramente exposta em seu trabalho sobre Hobbes de 1938).

O que queremos destacar é que, ainda que, desde a diversidade de seus contextos, tanto Hobbes como Schmitt entendem que o exercício da soberania estatal é a única possibilidade de neutralizar a conflitividade extrema. Um compreende e experimenta o estágio inicial da estatalidade; o outro, o esgotamento da vitalidade histórica do magno Leviatã. A seu modo, o que no primeiro poderia ser moderada esperança, ao que proporciona um respaldo teórico admirável, no segundo é um esforço por intentar resgatar o elemento teológico-político central da ordem soberana, para determinar de que modo pode cumprir sua função definitória na era da revolução, das massas, do nihilismo e do imanentismo consequente.

Para Schmitt, é evidente que esse esquema restou superado pelos acontecimentos. Não obstante, em seus escritos chave dos anos vinte, poderia encontrar-se não apenas uma aproximação do macroanthropos leviatãnico, senão também certa esperança de que alguns elementos da função catechônica (neutralizante e defensivo-conservador ou retardatária da crise excepcional) própria do Estado possam ser todavia operativas frente ao estado de exceção contemporâneo. Isso é evidente em sua exegese do 
artigo 48 da Constituição do Reich.

A confiança hobbesiana no futuro do Estado e a consciência schmittiana de que, não obstante a era da estatalidade esteja se encerrando, isto não conduz à total e à definitiva inanidade do aspecto central da soberania leviatânica: fazer convergir suas ideias no tema da representação. A seu modo, essa doutrina é a pedra angular do edifício estatal que um quer construir e o outro evitar que se derrube completamente.

Nenhum deles coloca o esquema legitimante em termos de dissolução do dualismo transcendência/imanência, nem dissolve os problemas que afrontam em torno da legitimação da autoridade em termos de racionalidade utilitária e de conexa elevação do compositum entre intercâmbio pacífico (horizontalidade contratualista do mercado e do diálogo) e violência desencadeada (contra o agressor irracional violento) a verdade das relações humanas, como se a legitimação e a efetivação da ordem vertical de toda convivência se resolvesse em termos de mera imanência. Pelo contrário, não apenas Hobbes, em sintonia com sua época, senão também Schmitt, na contracorrente da sua, desenvolvera, suas ideias respeitando a tensão entre fundamento último cristão e função utilitária como elementos determinantes da teleologia estatal (o ponto de condensação deste esquema é a relação entre leges naturalis e civiles, ou seja, entre Timor/amor Dei, ou seja, fé e obra segundo a Revelação, e Timor/amor dei mortalis; neste último caso, digamos: obediência e consenso).

Desse modo, essa familiaridade doutrinária não pode desconsiderar a diferença e a descontinuidade entre a visão hobbesiana e a schmittiana da representação. O jurista alemão não pode, nem entende que seja sensato, teorizar e sistematizar as categorias que secularizam o transcendente do mesmo modo como o faz Hobbes. O teórico da decisão excepcional pensa claramente desde a sociedade de massas em crise e é consciente não apenas de que o Estado clássico se extinguiu, senão também - o que é mais significativo - que isso acontece precisamente porque o desenvolvimento histórico trouxe as condições de realização daquela potencialidade dos elementos constitutivos da configuração 
originária da estatalidade leviatânica. Em todo caso, Schmitt entende que a pedra angular da construção estatal segue presente na capacidade de representação que tem a autoridade soberana, não em condições de normalidade, senão para enfrentar o estado de exceção. Seu problema será teorizar os contornos e as atribuições institucionais com que é, ou pode ser, o representante-soberano numa época na qual a soberania clássica desmoronou ante outras configurações do poder.

7. Desde a perspectiva que nos interessa, representar é estruturar o Estado, unificando legitimidade e legalidade e fundamentando, assim, todas as demais categorias que conformam o arcabouço jurídico da estatalidade em seus distintos níveis.

Ainda mais: a representação justifica que, apesar de (e, ainda mais, em virtude de) sermos todos iguais, alguns poucos mandem e outros muitos obedeçam, configurando-se, então, a relação de proteção-mandato própria de toda a ordem política, tendente a satisfazer o duplo imperativo da convivência, segundo a visão hobbesiano-schmittiana: o da prudência na ação soberana e o da obediência na atitude cidadã.

Mas além de como tenha sido a origem histórica do Estado, sua legitimidade se apoia sobre a racionalidade da soberania, à luz da argumentação hobbesiana: a teleologia do raciocínio justifica como meta a conformação de um dique de contenção a toda violência, procurando a segurança perpétua (Leviatã, I c.19) do cidadão. Daí a polêmica de Hobbes com o presumido direito inato de cada indivíduo de resistir ao regime civil toda vez que, segundo sua opinião pessoal não merece ser obedecido ou, diretamente, contra o qual cabe rebelar-se. Um passo decisivo, que faz da filosofia política hobbesiana um contratualismo quase anticontratualista é sua colocação de que o soberano no pacta, não deve ao celebérrimo contrato social a sua legitimidade, senão que ela provém do Deus Cristão, legislado e juiz único das obrigações e ações do mortal god. Nos termos estruturais do esquema hobbesiano, o soberano está caracterizado por uma sorte de exterioridade ao pacto em sentido estrito, que tem lugar ante ele e em função dele (i.e. das tarefas que o definem), porém sem 
ele. Hobbes não deixa dúvidas sobre o absurdo de todo o acordo horizontal quando não existe um nexo vertical de submissão dos contraentes a uma autoridade que garanta o cumprimento do acordado. Isto é fundamental: o que a tradição liberal moderna (e a pluralidade dos neocontratualismos contemporâneos) entende por contrato na filosofia hobbesiana põe uma ação impossível ou inútil. O Covenant é vão ou vazio quando não existe tal poder comum guardião da lei; por fim, não pode ser o ato de nascimento do poder público, como ocorre nas teorias liberais, que, ao refletirem diversamente fazem do povo o juiz das condutas soberanas. Sem soberano, os signos que expressam a intenção futura devem ser refutados como motivadores suficientes de uma ação; no estado de natureza a eventual força ilocucionária das palavras é uma farsa.

Em Hobbes, pelo contrário, enquando pensador moderno que faz da liberdade/igualdade uma marca antropológica básica, o momento do pacto é indubitavelmente expressão do consenso democrático (unânime e sem exclusão) que une e obriga, apenas e exclusivamente, aos que decidem serem súditos de que não toma parte na decisão de passar desde o estado de natureza à condição civil. Tomam-na apenas aqueles que renunciam ao direito natural (digamos: que abandonam suas armas), enquanto que o soberano é aquele que não as abandona, que não pactua e persiste em estado natural, empunhando sua espada. Obviamente, tal situação de disparidade que anula as duas premissas (desaparecem a igualdade e a liberdade) tem pleno sentido racional à luz da necessidade de viver em paz e em segurança, porque o soberano assume, como representante, o compromisso de utilizar a espada para garantir a ordem estatal como protetor dos que, ao desarmarem-se e aceitarem obedecer-lhe, tornam-se seus súditos. Todo este movimento não é um processo conceitual de legitimação a partir da gênese (ou seja, que não pode ser identificado com um esquema do tipo: o povo é a causa e o assim chamado soberano o juiz imparcial é meramente um efeito), senão que é próprio de uma composição estrutural de elementos numa correlação vertical (abaixo, os contraentes iguais entre si; acima, o defensor pacis). Trata-se do que 
Hobbes expõe como representación ${ }^{3}$.

O povo não é o mediador insuprimível e juiz das condutas de quem o povo acorda em eleger como autoridade (esquema própria das teorias do tiranicídio nos pensadores católicos da Contra-reforma, imediatamente feitas suas pelos doutrinadores lliberais, v.g. Locke). Nem sequer é tal, senão mera multidão, cujos componentes estão em estado de natureza. Porém, torna-se povo e se civiliza imediatamente quando aceitam um terceiro, exterior ao próprio acordo, como soberano, autorizam-no a que os representam, assumem o compromisso de aceitar como suas próprias condutas as que tomem o ator soberano, renunciado a desobedecer-lhe e a fortiori oferecer resistência a suas decisões (legislativas, executivas e judiciais) invocando juízos, opiniões, convicções pessoais, comprometendo-se a não levá-las ao espaço público sobre a base da crença emferma (cf. cap. 29) que seriam superiores e mais racionais porque emanam diretamente da consciência livre.

O motivo teológico político da representação radica-se em dois pontos deste esquema. Por um lado, a responsabilidade do soberano diante de Deus, juiz onipresente e justo, única autoridade superior ao deus mortal, que apenas a Ele deve prestar conta de suas decisões e ações. Por outro lado, as condições que possibilitam o acordo entre os que tornam-se cidadãos.

Enquanto o primeiro aspecto, se trata da já mencionada existência de um poder comum aos contraentes, porém distinto deles, que garante o cumprimento do acordo. O soberano esta ante aqueles, os quais decidem autorizá-lo a que os represente, gerando-se assim a relação entre autores e ator-representante (Lev., cap. 16). Este tipo de harmonização entre essas duas instâncias é já uma cruz entre a horizontalidade do acordo e a verticalidade da soberania que dá sentido ao próprio pacto. Cabe insistir: esse não ratifica nem gênese nem legitimação da soberania no

É sabido que o ponto nelvrágico é o capítulo 16 do Leviatã; a fundamental propedêutica categorial é principalmente os capítulos 13 a 15 .

Ano $13 \cdot$ n. $1 \cdot$ jan./jun. $2013-27$ 
sentido e função precisa que esta figura horizontal por excelência cumpre no liberalismo. A rigor, poderia dizer-se que, como ato de nascimento e legitimação da soberania, o contrato social, para Hobbes, é impossível, pois necessita do soberano para ter lugar, e, se tem lugar, então não pode ser considerado como geração e justificação da soberania legítima. Trata-se, ao contrário, de um reconhecimento do soberano e uma aceitação por parte deste da responsabilidade que isso significa, porém não é o contratualismo em sentido estrito, pois não há uma posição horizontal comum a pactuantes (que renunciam ao ius naturalis) e o soberano (que não renuncia e por isso está em relação vertical de superioridade com referência a eles). 4

8. O contratualismo moderno herda a tradição cristã da soberania popular gratia Dei e da dependência do eleito em face do povo eleitor; um modelo que cumpre na modernidade a função de justificar a rebelião e a guerra civil (seja nos pensadores da Contra-reforma, reciclando a velha doutrina do tiranicídio; seja nos liberais, entre os quais Locke é paradigmático na recepção silenciosa - de doutrinas jesuítas e sua concretização em chave liberal.

Não é o caso de Hobbes, que rechaça essa colocação, porque da mesma não surge um autêntico soberano, senão uma autoridade administrativa submetida - em sua legitimidade tanto de origem como de exercício - aos juízos pessoais de quem

Esta primeira condição de possibilidade, então, põe em evidência que a associação entre iguais supõe um não igual que aceita ser garanta deste acordo; isto é, os primeiros são súditos, estes sim, graças ao pacto, porém o segundo simplesmente assume as orbigações e tarefas políticas da representação: deve operar a mediação entre a universalidade humana das leis naturais e a universalidade política (ergo estatal) das leis civis, sendo responsável diante de Deus da prudência com que o faz e de como o garante, assim, a validade e a vigência do acordo horizontal de seus autores-representados. Se não teme e obedece ao Senhor, se não cumpre com a eticidade cívica que se depreende da significação cristã do mundano e secular, não é soberano. É um louco [Foole] e um ateu que ocupa uma posição que não lhe cabe (infra retomamos esta figura e remeteremos às passagens correspondentes). 
devem obedecer-lhe; juízos que expressam um desacordo, pois vêm afetados de seus particularismos, porém - para Hobbes não tem mais validade que a própria do natural pré-civil, isto é, de tudo o que termina inevitavelmente fomentando o conflito. $\mathrm{O}$ primado do político (tanto natural - leges naturales - como civil leges civiles ou positivas) sobre o natural (liberdade, com a única obrigação expressa no imperativo da autopreservação), a cesura extrema e ruptura de continuidade, diretamente a antítese entre as duas situações, em suma: este dualismo radical entre o anti-político e o político e a preeminência dessa segunda condição sobre a primeira supõe uma renúncia coletiva ao direito natural de cada um, o qual não é senão um modo de expressar o reconhecimento por parte dos renunciantes de que, se ante eles está empiricamente presente alguém que é igual a eles como ser humano, sem dúvida, já não é um igual desde a perspectiva teológico-política que sustenta a legitimidade do Estado, senão um ator político e jurídico superior: o soberano representante. Os dois corpos do soberano. Reconhecê-lo como tal é aceitá-lo: assumir o compromisso de obedecê-lhe, para ser por ele protegido, que é correlativo ao compromisso do soberano diante de Deus exclusivamente de que suas decisões e ações buscaram proteger e pacificar a convivência estatal. Este é o sentido do pacto: os que deram sua palavra de obedecer serão castigados pelo soberano se a violarem; tal como o soberano será castigado por Deus se não cumpre com sua responsabilidade: interpretar as leis naturais e particularizá-las como leis civis, para aplicá-las e castigar a quem não as cumpre. A representação, sístole e diástole do corpo estatal, é uma relação metafísica corporizada, um, um universal encarnado. ${ }^{5}$

5 Não se trata de uma consideração própria da história das ideias, a de mostrar a derivação como um fato acontecido, porém nada mais. Pelo contrário, a teologia política se vivifica no seio mesmo dos conceitos e reflexões hobbesianas para legitimar o que ele entende por soberania. Apenas a mediação que a perspectiva teológico-política oferece enquanto secularização da teologia e conformação do político antes de sua redução ao administracionismo tecnocrático presidido normativamente por um juiz imparcial que faz respeitar as leis naturais do socioeconômico resolve o

Ano 13 • n. 1 • jan./jun. 2013 - 29 
Seu sentido básico é o de estar no lugar do outro, de maneira tal que a alteridade é simultaneamente identidade. Entendido em seu conceito teológico-político, opera uma derivação secularizante a partir do dinamismo trinitário. A dignidade religiosa e a ética cristã têm a representação em sua correspondência analógica com a Segunda Pessoa da Trindade. A presença do Redentor reverbera, secularizada, na figura do representante-soberano; assim como a fundação da Igreja por Cristo o faz, também mediante a secularização moderna, na do Estado. A Segunda Pessoa encarnada para redimir o gênero humano dá início ao caminho da salvação na Igreja que Jesus Cristo funda. Estes mistérios e dogmas de fé básicos tornam-se - insistimos: secularizados, porém, no século XVII, todavia não aniquilados - conceitos que, em pensadores diversos com posições não imediatamente assimiláveis, legitimam instituições e categorias políticas e jurídicas, à medida que possibilitam solidificar a coerência estrutural entre a transcendência e a imanência à luz dos problemas que coloca a convivência secular numa época de crise religiosa, guerras e desmoronamento dos saberes e das crenças tradicionais. No caso de Hobbes, além de marcar a especificidade das categorias com que legitima o Estado, justificam a solução protestante que lhe dá ao problema da tensão constante (senão o conflito que em sua época desemboca numa violenta guerra civil) entre potestade eclesiástica e potestadade secular: o soberano concentra a ambas, é cabeça do Estado e da Igreja ao mesmo tempo.

Enquanto a outra condição de possibilidade, regressaremos ao momento do pacto de relação convivencial que estabelecem aqueles que abandonam a racionalidade instrumental mobilizada pelo interesse pessoal em sentido imediato e egoísta, para submetê-la à racionalidade política da representação, que

que de outro modo seriam aporias à reflexão hobbesiana, tendo em conta a antropologia negativa que está na base de seu pensamento e que exalta a autossuficiência da racionalidade utilitária para explicar o poder civil, precisamente como instrumento útil para proteger desde fora o intercâmbio de ideias e produtos, a saber, o dinamismo natural dos seres humanos enquanto humanos.

30 - Universidade Católica de Pernambuco 
não anula a importância do benefício pessoal, obviamente, senão que o integra aos sistemas legislativo, executivo e judiciário do Estado, posto que à potestade soberana cabe interpretar o significado desse interesse. No acordo horizontal, o momento teológico-político determina (em que pese a argumentação hobbesiana não o destaque como deveria) que o pacto pode ter lugar não apenas porque o soberano garante, senão também por que os contraentes já tenham mudado sua predisposição espiritual, sua consciência, ou seja, que não são os mesmos descritos como imersos no estado de natureza belicoso, sua condição natural é outra: não são livres, senão que estão obrigados pelas leis naturais. Sem esta dualidade, a questão política não teria sentido.

9. A rigor, Hobbes não explica o processo que leva a que cada indivíduo em condição natural leve a cabo em sua personalidade íntima a reversão de sua condição de ser livre à de ser obrigado.

Para sua tarefa de legitimar o Estado, não se necessita dar explicação. Daí que não ofereça uma psicologia ou algo parecido da mudança espiritual desde a liberdade à vida civilizada, do direito natural à estatalidade. $\mathrm{O}$ que se faz é expor os princípios e as categorias que possibilitam (as condições de possibilidade) e justificam essa mudança, que é precisamente teológico-política, pois o passo chave é próprio da adoção da fé cristã, da crença em Deus Legislador como fonte das leges naturales e como Juiz certeiro e justo que não pode ser enganado por quem não cumpre seus compromissos nem obedece a lei quando não corre perigo de ser castigado por Ele. A passagem é de submissão direta às leis de Deus no estado de natureza (neutralização do ius, abandono da libertas) à submissão as leis civis através da aceitação do mandato soberano, no estado civil, porque - cabe reiterá-lo - estas leis civis são a concretização política das naturais.

Tanto a submissão do soberano à potestade divina como a fé e a consciência religiosa e, por fim, cívica do cidadão são os pilares teológico-políticos do Estado barroco e da conexa soberania. Mais ainda, o cidadão que trabalha acata a lei de maneira apenas exterior, porém que está disposto a violar a lei apenas seu 
juízo pessoal sobre a conveniência egoísta não o leve a desobedecer e violar seus compromissos, é também um néscio que raciocina segundo a utilidade natural ainda quando a norma a tenha invalidado, e que se aproveita das falhas, imperfeições e falências na tarefa soberana regida pelas leis naturais e civis em desmedro do compromisso republicano; em suma, quem não cumpre a lei se as circunstâncias são tais que pode escapar ao castigo dos homens trabalha segundo a razão natural, porém contra a superior razão civil, nega desta maneira a Deus, fundamento legitimador da soberania, a saber, da convivência pacífica e segura. ${ }^{6} \mathrm{O}$ ensinamento hobbesiano é que o louco e o ateu não podem viver na república, porque seria cobiçar um inimigo disposto a agir como tal apenas tenha ocasião.

Por certo, abre-se aqui o problema do caráter de respublica christiana que tem o Leviatã. Essa condição se explica em função da solidez argumentativa, ou debilidade, da interpretação que estamos propondo (sucintamente, por certo). Cabe observar desde já que nos centramos em figuras e reflexões dos capítulos nos quais Hobbes expõe a - digamos - racionalidade, sim, mas da estatalidade em termos que não seriam diretamente cristãos ou que não são apresentados como tais (isto é, atendemos aos últimos três capítulos da primeira parte e à segunda parte; na terceira se ocupa, ao contrário, do "Christian Commonwealth", em particular). Entendemos, de todas as formas, que, já neste momento

6 Lev., XXIII, "For instruction of the People"; XLII, "The question of Superiority between the Pope and other Bishops" (no Leviatã em latím, a fórmula é "Potestas enim legitima omnis a Deo est", cf. Opera Philosophica Omnia, ed. Molesworth, III, p. 419); De Cive, XII, 3 ("Quare enim appellas tu tyrannum, quem Deus regem fecit, nisi tu, privatus exsistens, cognitionem ad te trahas boni et mali?"); Behemoth, I Dialogue in fine ("the civil laws are God's laws, as they that make them are by God appointed to make them; [...] the King owes his crown to God only, and to no man, ecclesiastic or other; [...] the King's laws are God's laws"). Na capa da edição parisiense (1642) do De Cive, tem um lugar destacado o provérbio bíblico $(8,15)$ que resume estas questões "Per me Reges regnant et legum conditores iusta decernunt". Sem Deus omnipotente e criador, "First Mover", se desmorona a racionalidade causal, e com ela a lei (Lev., XII, "Of Religion"). Nietzsche o confirma, para invalidar-lo.

32 - Universidade Católica de Pernambuco 
de sua exposição, se faz evidente a dívida doutrinária que o Estado hobbesiano tem com o cristianismo como mediação entre o universal transcendente e o particular imanente, que traz consigo uma disposição do ser humano, que é absolutamente necessária para que o raciocínio hobbesiano seja coerente. Que sua filosofia política seja paradigmática da teologia política como saber próprio do processo de secularização realça a dívida com a dignificação cristã do político em termos irredutíveis à racionalidade instrumental-utilitária, a qual, de acordo com as próprias premissas de Hobbes, não pode dar conta dos encadeamentos conceituais na legitimação da soberania.

Assim resta claro que a Encarnação e a morte na cruz é o evento que dignifica a política: Cristo fundador da Igreja é condição de possibilidade teológico-política da representação estatal, à medida que a estrutura categorial básica do Estado em Hobbes remete à fé cristã para que os diversos momentos e categorias do raciocínio tenham o sentido que sua função argumentativa exige. ${ }^{7}$ A representação radica na função soberana como vicário de Deus e como ator autorizado pelos cidadãos representados por e graças a Ele: sua vontade da unidade, unicidade e organicidade ao "Bodie Politick", com a ressalva de que o aspecto fundamental (e entendemos que não é menos evidente em que pese a argumentação hobbesiana não o destaque como deveria) é que os contraentes podem pactuar porque não são os mesmos do estado de natureza belicoso. Sobre o direito inato de todos a tudo se tem imposto a lei e sua obrigação anuladora da liberdade, a lei tão natural como esse direito sobre ele que prevalece. Esta prevalência da lei e a

$7 \quad$ Porém, isto não exclui em absoluto o pertencimento à cidadania estatal de crentes em outras religiões monoteístas, à medida em que o objeto de sua fé, a divindade transcendente, compartilhe traços teológicos que as distingue de outros tipos de religiosidades. Ainda que um crente não compartilhe a peculiar legitimação cristã da representação estatal, se sua conduta é de obediência à lei civil, nada impede conceitualmente a que seja membro pleno da república do leviatã: nada há nele de louco ou ateu. Seria antipolítico refutá-lo. Em todo caso, o problema é a fidelidade no caso extremo, no estado de exceção, quando o argumento de utilidade pode contrariar o cumprimento da lei.

Ano $13 \cdot$ n. $1 \cdot$ jan./jun. $2013-33$ 
consequente dignificação da convivência supõe que no ser humano prevalece a fé cristã por sobre o impulso meramente utilitário ligado à racionalidade instrumental; somente como mandamentos divinos podemos cumprir as leis naturais, que obrigam tanto aos cidadãos como ao soberano por igual, apesar de que a este o obrigue diretamente frente a Deus, enquanto que aqueles os ponham, enquanto cidadãos, ante o deus mortal-representante, e, enquanto cristãos, ante o mesmo soberano porém qua príncipe da Igreja, e através dela, ante Deus. Fé cristã, então, porque apenas a Encarnação do Cristo, ao dignificar a Terra desde o Céu, abre para a vida estatal um sentido não exclusivamente utilitário e imanente em geral e dá sentido à uma ética cívica que complementa à fé religiosa, de cuja simbiose na consciência depende a possibilidade da vida civil. A seu modo, a passagem da natureza inóspita e perigosa à vida em comunidade, pacífica e segura, é um batismo secularizado: neutralizar (não extirpar) sua natureza passional pragmática ao aceitar os mandamentos divinos volta ao ser humano consciente do suporte transcendente do Estado e dá sentido à obediência ao que manda (legisla, executa, julga) porque protege. E disso é responsável ante Deus. O não crente não pode ser cidadão; quem não crê em seu foro íntimo deve comportar-se como se o fosse, ainda que seu civismo exterior seja frágil. Sem esta fé, nem os homens saem do estado natural, porque o pacto é absurdo, nem o soberano é tal, porque será arrastado por paixões egoístas e se tornará um déspota.

\section{Retomamos observações já feitas, porém, atendendo aos textos. Hobbes se expressa claramente a este respeito}

A renúncia ou transferência do direito "is a Declaration, or Signification, by some voluntary and sufficient signe, or signes, that he doth so Renounce, or Transferre [...]. And the same are the Bonds, by which men are bound, and obliged: Bonds, that have their strength, not from their own Nature, (for nothing is more easily broken than a mans word,) but from Feare of some evill consequen- 
ce upon the rupture" (pp. 191-1928). "If a Covenant be made, where in neither of the parties performe presently, but trust one another; in the condition of meer Nature [...] upon any reasonable suspition, it is Voyd: But if there be a common Power set over them both, with right and force sufficient to compell performance; it is not Voyd. For he that performeth first, has no assurance the other will performe after; because the bonds of words are too wak to bridle mens ambition, avarice, anger, and other Passions, without the feare of some coerceive Power", inexistente en el estado de naturaleza, donde "he which performeth first, does but betray himself to his enemy $[\ldots]$. But in a civill estate $[\ldots]$ that feare is no more reasonable" (p. 196).

"The Force of Words, being (as I have formerly noted) too weak to hold men to the performance of their Covenants; there are in mans nature, but two imaginable helps to strenghten it. And those are either a Feare of the consequence of breaking their word; or a Glory, or Pride in appearing not to need to break it. This is a Generosity too rarely to be found to be presumed on [...]. The Passion to be reckoned upon, is Fear; whereof there be two very generall objects: one, The Power of Spirits Invisible; the other, The Power of those men they shall therein offend. Of these two, though the former be the greater Power, yet the feare of the latter is commonly the greater Feare. The Feare of the former is in everyman, his own Religion: which hath place in the nature of man before Civill Society. The later hath not so; at least not place enough, to keep men to their promises; because in the condition of meer nature, the inequality of Power is not discerned, but by the event of Battell. So that before the time of Civill Society, or in the interruption thereof by Warre, there is nothing can strengthen a Covenant of Peace agreed on [...] but the Feare of that Invisible Power, which they everyone worship as God; and Feare as a Revenger of their Perfidy" (p. 200). "[...] a Covenant, if lawfull, binds

Todas as páginas remitem a Thomas Hobbes, Leviathan. Edited with an Introduction by C. B. Macpherson, Penguin Books, London, 1985.

Ano $13 \cdot$ n. $1 \cdot$ jan./jun. $2013-35$ 
in the sight of God [...]: if unlawfull, bindeth not at all" (p. 201).

A Fé religiosa a respeito das leis naturais tem um significado concreto, ligado à condição de momento de transição de uma naturalidade anticivil: não é mera crença íntima, circunscrita ao foro interno, senão a motivação de um esforço e da resultante disposição para que o foro externo seja regulado por elas, na forma de leis civis:

\footnotetext{
"They oblige onely to a desire, and endeavour, I mean an unfeigned and constant endeavour, are easie to be observed. For in that they require nothing but endeavour; he that endeavoureth their performance, fulfilleth them; and he that fullfilleth the Law, is Just"' (p. 215)
}

A lógica da obrigação à luz de uma razão natural não guiada pela lógica belicosa do estado de natureza é inútil e prejudicial, pois ensina uma utilidade que não é tal se impera o direito natural nas relações humanas. Para que a renúncia ao direito natural não equivalha a tornar-se vítima do outro que, com suas palavras, poderia estar enganando-o ao dizer-lhe que ele também disporá de seu direito (e tem direito a enganá-lo), o conteúdo racional das proposições que ensinam como assumir obrigações e quais são elas, que em si mesmo é insuficiente para dar realidade ao que ensinam, deve ter a forma de lei. E apenas o tem por ser mandatos de Deus, único legislador antes de seu representante, o soberano. O racionalista ateu permanece em estado de guerra de todos contra todos, ainda que não o seja e ainda que trabalhe como os cidadãos que compreendem que sem legislador não há obrigação e que prévio a, e condição de possibilidade da legislação civil, apenas há a legislação política, não física, proveniente de um Deus que, ao apresentar-se encarnando-se, tenha fundado igreja e tenha dignificado a representação como ordem secular das coisas seculares, como mediação teológico-política entre transcendência e imanência: 
"These dictates of reason, men use to call by the name of Lawes; but improperly: for they are but Conclusions, or Theoremes concerning what conduceth to the conservation and defence of themselves; whereas Law, properly is the word of him, that by right hath command over others. But yet if we consider the same Theoremes, as delivered in the word of God, that by right commandeth all things; then they are properly called Lawes" (pp. 216-217).

Considerar a pedagogia racionalista como mandatos divinos não é um expediente retórico, senão que remete ao significado (recém-indicado) que tem o cumprimento das leis naturais: crer no Deus legislador, esforçar-se para que suas leis ordenem o século (paradoxalmente: o homem é livre e pecador, por isso as leis naturais divinas não regem como as físicas; porém, a resposta hobbesiana é não menos paradoxal: ser livre não por natureza, senão por vontade equivale a tomar a decisão de renunciar a liberdade natural porque é prejudicial à obrigação superior da criatura humana: preservar-se e preservar a espécie). Esta renúncia apenas tem sentido quando um terceiro está presente por fora do grupo que pactua, porém ligado a ele como condição de possibilidade de que estipulem o acordo, aceitando que seja seu representante. Todos estes aspectos confluem na crítica hobbesiana ao louco e ateu:

"The Foole hath sayd in his heart, there is no such thing as Justice; and sometimes also with his tongue; seriously alleaging, that every mans conservation, and contentment, being committed to his own care, there could be no reason, why every man might not do what he thought conduced thereunto: and also to make and not to make; keep, or not keep Covenants, was not against Reason, when it conduces to ones benefit".

O néscio não nega a existência dos pactos e a definição nominal de justiça,

"but he questioneth, whether Injustice, taking away the feare of God, (for the same Foole hath said in his he- 
art there is no God,) may not sometimes stand with that Reason, which dictateth to every man his own good", sobretudo se lhe permite liberar-se do poder de outros humanos (p. 203).

A representação hobbesiana revela o perigo que contém o utilitarismo compreendido em sua pura racionalidade: fomentar a guerra civil.

"The Kingdome of God is gotten by violence: but what if it could be gotten by unjust violence? were it against Reason so to get it, when it is impossible to receive hurt by it? and if it be not against Reason, it is not against Justice: or else Justice is not to be approved for good" (p. 203).

Mais adiante, prossegue conectando seu discurso com o precedente:

"For the question is not of promises mutuall, where there is no security of performance on either side; as when there is no Civill Power erected over the parties promising; for such promises are no Covenants: But either when one of the parties has performed already; or where there is a Power to make him performe; there is the question whether it be against reason, that is, against the benefit of the other to performe, or not. And I say it is not against reason".

Em termos de utilidade natural não convém pactuar, pois nada assegura o cumprimento; em termos de utilidade civil, se apenas que neste caso não é um pacto conforme a horizontalidade que iguala os contraentes segundo o direito civil e a economia; trata-se de um reconhecimento de uma superioridade de um por parte de muitos.

Antes de tudo porque não se produz a relação de representação, se persiste na insegurança extrapolítica. Somente para que essa relação se produza, a utilidade civil não é suficiente, já que supõe o que necessita para ter sentido: a preeminência da obediência à lei natural sobre o direito natural à liberdade absolu- 
ta. Para que se imprima a obediência, a lei natural tem que ser lei em pleno sentido do termo: uma produção legislativa acompanhada de coação e pena a quem a viole. Isto supõe um soberano cujo caráter absoluto como tal, seja superior ao do soberano civil, do qual é condição de possibilidade. Essa Rei de reis é Deus: se não se acredita Nele e se trabalha em consonância para a lei natural tenha validez e vigência no foro externo, i.e., que ela se torne lei civil, se persiste no estado de natureza. É o que acontece tanto com quem viola a lei quando não há possibilidade fática de que o descubram, como e, sobretudo com os rebeldes e revolucionários. No texto do capítulo 15, a argumentação contra os néscios e ateus recorre a argumentos variados (desafiar o previsível, i.e. ser castigado, não se justifica ainda quando haja casos de descumprimentos não penalizados; no estado de natureza há que entrar na lógica da representação porque a guerra exige alianças, e enganar os Confederates é prejudicar-se a si mesmo); porém, as confederações mais interessantes são as relativas à atitude republicana para com os conservadores para com os demolidores da república: impedi-los de ser parte dela.

"He therefore that breaketh his Covenant, and consequently declareth that he thinks he may with reason do so, cannot be received into any Society, that unite themselves for Peace and Defence, but by the errour of them that receive him; nor when he is received, be retayned in it, without seeing the danger of their errour"

De modo que se isso não ocorre, "it is by the errours of other men”, o qual não é um argumento a favor do néscio. "As for the argument of gaining the secure and perpetuall felicity of Heaven, by any way; it is frivolous: there being but one way imaginable; and that is not breaking, but keeping of Covenant. And for the other Instance of attaining Soveraignty by Rebellion;", pode suceder que aconteça, porém não é razoavelmente previsível, e para pior se volta um exemplo imitável e, por fim, perigoso para o usurpador exitoso. Ao qual advoga que, quem acredita que rebelando-se ganha o céu, supõe um conhecimento que é impossível: 
que acontece post mortem. "Breach of Faith cannot be called a Precept of Reason, or Nature". A conclusão (a rigor expressa antes de citação precedente) é que "Justice therefore, that is to say, Keeping of Covenant, is a Rule of Reason, by which we are forbidden to do any thing destructive to our life; and consequently a Law of Nature" (pp. 205 y 206).

A racionalidade da realização do contrato se sustenta por si só. A dimensão política desta racionalidade, em vista da qual legitima o Estado, supõe que ademais de ser um preceito, seja uma lei.

Entendemos que este aspecto, decisivo para o tema da decisão e da ação consequente inerentes ao mecanismo da representação, responde à uma colocação teológico-política, que articula fé, medo e obediência através da analogia entre Deus transcendente e deus mortal; uma analogia que, historicamente, significa que a teologia é secularizada e que a política não matou a Deus.

11. Sigamos agora outros aspectos de nossa leitura, os quais estão certamente ligados ao sentido que a derivação de um âmbito, o teológico, ao outro, o político adquire na colocação hobbesiana, primeiro, e após, na recepção schmittiana do mesmo, que não tematiza e ou não coincide com vários dos aspectos que temos assinalado.

Se Hobbes dá a entender com claridade, ainda que com uma argumentação complexa, sua ideia (ou seja, o que interpretamos como tal) de que a soberania responde à uma mediação na cruz entre o transcendente religioso e o imanente utilitário; uma mediação segundo a qual a legitimidade da representação e do soberano-representante provém desde cima, via legalidade natural como mandato divino e tudo o que disto se segue, na forma da legalidade civil que descende ao povo, por um lado; e, por outro, o Estado acolhe, a guisa de receptáculo regulador, o consenso e a obediência que ascende desde baixo, então cabe agora assinalar que Schmitt lê Hobbes desde uma perspectiva menos orgânica. Por certo, destaca os componentes vetero-testamentários e suas tensões com os pragmático-instrumentais na construção do Le- 
viatã, porém o aspecto chave para a questão teológico-política como um dos eixos de seu hobbesianismo passa pelo que (com algum atraso, mas na formulação, que na ideia) chama a abertura à transcendência no teto de cristal de Hobbes ${ }^{9}$.

A rigor, Hobbes está presente, com maior ou menor visibilidade, no recorrido intelectual schmittiano ao largo das vicissitudes da totalização inerente à sociedade de massas e liquidadora da estatalidade, primeiro na República weimeiriana e logo na nefasta ordem totalitária. A teologia hobbesiana subjaz em maior ou menor medida tacitamente em suas considerações anteriores a 1938; forma um elemento - não devidamente priorizado, diríamos - no livro desse ano - e recentemente encontra um tratamento nítido e sugestivo, como assinalamos, no "System-Kristall" que enriquece a re-edição (1963) do Conceito do político, na versão de 1932, e no artigo sobre "O cumprimento da Reforma”, de 1965.

Cabe observar, de todos os modos, que seu pensamento ius-filosófico sobre a dimensão teológico-política das categorias e realidade do Etsado moderno se movem num plano argumentativo que não é o mesmo em que teoriza a representação desde o direito constitucional, de onde também discute o sentido da condição de representante num esquema como o da Constituição de Weimar. Na Doutrina da Constituição (1928), as análises schmittianas da representação desenvolvem as premissas intrinsecamente jurídicas, aporta sugestões interpretativas e destaca a genealogia histórica desta noção, porém não se limita a contrapor às explicações habituais, de corte utilitário, outra ideia de Räpresentation, sem aprofundizá-la. A discussão sobre o sentido do exercício soberanos em casos de extrema necessidade, nos Ausnahmezustände e, por fim, um discurso mais estritamente jusconstitucionalista resultam prioritários.

Cf. A Indicação que Schmitt agrega a re-edição feita em 1963, do Conceito do político (versão de 1932), ampliando as considerações de pp. 59-66 de Der Begriff des Politischen. Text von 1932 mit einem Vorwort und drei Corollarien, Duncker u. Humblot, Berlin, 1963, pp. 121-123.

Ano $13 \cdot$ n. $1 \cdot$ jan./jun. $2013-41$ 
Em todo caso, o que é comum a Hobbes e a Schmitt (e a ligação conceitual entre eles é Hegel) é que oferecem a justificação teórica da independência e superioridade conceitual do fundamento da soberania com respeito à lógica intrínseca das teorias antes de tudo socioeconômicas e em consequência também político-jurídicas liberais.

O Estado, como instituição jurídica conforme os princípios básicos da antropologia metafísica da modernidade (dado que, como humanos, somos por natureza livres e iguais, ingressamos no espaço artificial da política nas mesmas condições: uma cabeça, um voto). O modelo estatal teve, sem dúvida, uma solidez efêmera: Hobbes não vivenciou a dissolução niilista da transcendência sobre a qual se legitima seu leviatã; Schmitt, ao contrário, experimentou a dissolução da estatalidade pelo niilismo.

Por isso, se ambos reconhecem que o momento de consentimento é necessário para que uma ordem política moderna conte com bases firmas para seu desenvolvimento, a legitimidade da suma autoridade tem que ter sua razão legitimante primeira e última no monopólio da interpretação e concretização executiva dos princípios existenciais fundantes da existência coletiva que devem proteger, instaurar e ou restaurar. Isso conduz, em Hobbes, à condição de representante do Deus Imortal que tem o deus mortal ou soberano estatal; em Schmitt, a condição de soberano absoluto para as situações críticas extremas, ou estados de exceção, da qual deve gozar a personalidade no topo da pirâmide estatal (e que o Presidente do Reich, de acordo com a Constituição weimariana, devia desempenhar na continuidade doutrinária com a figura do monarca constitucional das repúblicas - dada a divisão dos Poderes - em alguns regimes do século XIX, e já em seus posteriores, inclusive no século XX.

Ainda que nossos filósofos proponham uma mediação entre o poder estatal e a autonomia da pessoa que é diversa à do liberalismo (no sentido rigoroso desta filosofia política e econômica), sem dúvida, não por isso é menos idiossincraticamente moderna, pois objetiva responder a problemas e crises históricas que logo se colocam na modernidade em sua fase clássica, para 
adquirir uma dimensão explosiva com a sociedade de massas. Tanto Hobbes como Schmitt assumem que a alternativa inevitável ao modelo de Estado que estes propõem (no que à sua dívida com o transcendente, para além dos óbvios sinais específicos que partilham) é uma conflitividade que, no mundo moderno, pode manter-se latente ou incipiente, porém que não deixa de estar sempre presente e termina desencadeando-se, que efetivamente acontece, até alcançar seu paroxismo na guerra total, de varia morfologia até o presente.

12. A teoria teológico-política da representação justifica, então, o nexo de mandato-obediência, porém não já em qualquer sistema político, senão especificamente no Estado, uma configuração cuja marca moderna por excelência é uma paradoxal resolução política da originária ficção não-e-anti-política: uns mandam e outros obedecem porque todos são livre por natureza.

A partir deste pressuposto, o problema da representação em Hobbes é o de neutralizar a convicção das consciências livres, saber: que cada uma tem o direito natural a interpretar as normas transcendentes e manter vigente esta interpretação privada também quando se torna cidadão, pois ela pode justificar sua desobediência quando sua opinião resulte incompatível com a do soberano e se veja avassalada por esta última. Isto é, que persiste sua racionalidade pré-política, natural, e a conseqüente tendência a desconfiar primeiro e a desobedecer depois ao soberano.

A marca cristológica neutralizadora da desobediência é evidente em que a representação, antes de ser a do povo na figura do representante, o ator representando aos autores, é a do deus mortal como representante do Deus imortal, quando legisla e executa as normas positivas que são a interpretação e aplicação das leis naturais ou divinas. É graças a esta representação instituída e operada verticalmente que o povo está em condições de consentir a ser representado pela pessoa soberana, a qual não participa do acordo pelo qual aqueles que desde este momento tornam-se seus súditos abandonam sua condição natural de mera multidão associada para a guerra, porém incapaz de viver pacificamente como povo. O que significa que Hobbes assume como premissa do mo- 
delo leviatânico como esforço de contensão e disciplinamento do povo a mesma subjetividade que denuncia como a causa da desordem e da belicosidade; isto é, acredita que é possível insuflar ao eu auto-ungido à fundamento, um respeito temeroso capaz de submeter-se seu orgulho, a hybris da subjetividade. Tal tarefa é a do representante, quem deve imunizar o corpo político deste veneno das doutrinas sediciosas que sustentam que cada indivíduo em sua privacidade é juiz das ações boas e más e que o fato contra a própria consciência é pecado, e assim laenta o orgulho e a desobediência, cujo primeiro passo consiste em fazer-se a si mesmo juiz do bem e do mal, em que pese viver no seio de uma ordem soberana. 10

Hobbes legitima a república levitânica (o Commonwealth monárquico ou aristocrático, ainda que conceitualmente admita também a democracia) como dispositivo pacificador que tem na pessoa soberana o mantenedor da ordem, protetor em condições de normalidade mediante suas decisões ordinárias (leis, normas executivas variadas, sentenças e disposições judiciais, etc); porém, que pode e deve fazê-lo porque antes (ou seja, em termos de aprioridade conceitual e prática concreta) responde com decisões excepcionais às condições extraordinárias de crises imprevisíveis, a conflitividade irrestrita da guerra civil e internacional, o mais profundo dos desafios postos ao Estado.

Schmitt, por sua vez, experimenta a guerra total em sua eclosão definitiva, própria da sociedade de massas, o niilismo e a totalização, na pluralidade de seus atores e manifestações e com o resultado de que restam efetivamente canceladas as distinções existenciais e funcionais entre espaços diversos da convivência estatal. Um conflito que, se por um lado é inerente ao ser humano, por outro encontra sua manifestação por antonomásia na guerra civil-internacional moderna e contemporânea. Hobbes a conheceu em sua faz inicial como guerra religiosa, proléptica e detonadora

\footnotetext{
10 Leviatã, cap. 29, pp. 365-366 (parágrafos "Juízo privado sobre o bem e o mal” e "Consciência errônea").

44 - Universidade Católica de Pernambuco
} 
da lógica do Estado como ordem desativadora, neutralizadora do enfrentamento (mediante a soberania absoluta, a obediência consensuada, a resignação e a despolitização dos espaços societais, tornando-os aptos para o intercâmbio horizontal de ideias, opiniões, produtos, trabalhos e serviços). Schmitt a experimentou em sua concretização plena, como guerra total no século vinte.

Desde esta perspectiva, reiteramos que Hobbes expõe o Estado clássico no momento histórico de sua gênese e almeja oferecer uma legitimação capaz de harmonizar o princípio da legitimidade tradicional com o consenso democrático moderno; e Schmitt no do fenecimento do mesmo Estado moderno, e busca destacar os elementos centrais a respeitar no caso o que for necessário revitalizá-los na era das massas, do elitismo tecnocrático e ideologizado e da totalização irrestrita, em que se tem desmoronados as distinções espacial-existenciais entre o público estatal, o público-societal e o privado pessoal, que a representação perpassa verticalmente.

Poderíamos acrescer que Schmitt, ao final do ciclo estatal, está consciente de que seu admirado antecessor não podia compreender nos começos do mesmo processo, a saber: que o Estado nasce morto. Isto é, compreende claramente que o processo de totalização que irrompe na história com a sociedade de massas tem conduzido a mutações para uma estrutura modelada sobre a base de uma legitimação teológico-política, ainda quando pode conservar a esperança, se se quer: a ilusão de que a estatalidade pode manter algum tipo de vigência, em que pese o fundamento da soberania tenha permanecido desativado e que se tenham derrubado nas doutrinas e nas práticas, tanto as diferenças entre os âmbitos existenciais intra-estatais, como no pluralismo de unidades soberanas no plano internacional. 